\title{
Analysis on the Application of "Micro - education Mode" in Table Tennis Teaching
}

Shunjia Bi

\section{Zhuhai College of Jilin University, Zhuhai Guangdong 519041}

\begin{abstract}
Table tennis has always been the sports with Chinese people's pride, it is an indispensable important content in sports teaching. With the continues improvement of China's comprehensive national strength, the level of education also rises, and table tennis teaching has gradually highlighted its deficiency. The deficiency has some restrictions on improving the students' table tennis level. The use of micro education model in table tennis education has played a significant effect in improving quality of table tennis teaching, and provides students with their own teaching mode. This paper discusses the necessity of the application of "micro education pattern" in table tennis teaching and the concrete implementation suggestion, and provides a good environment for students to learn table tennis.
\end{abstract}

Keyword: Micro - Education mode; Table tennis teaching; Teaching advice

\section{浅析“微教育模式” 在乒乓球教学中的应用 毕顺家 （吉林大学珠海学院，广东珠海 519041)}

摘要: 乒兵球一直是国人引以为傲的体育运动, 是体育教学中不可或缺的重要内容。我国的综合国力不断提高, 教育水 平也随之上升, 兵兵球教学也逐渐凸显出其中不足。这些不足对于学生们兵乓球水平的提高具有一定的限制。微教育模式在 兵乓球教育中的运用，对兵兵球教学质量的提高起到了显著效果，为学生们提供了适合自己的教学模式。本文对 “微教育模 式”在兵兵球教学中应用的必要性以及具体实施建议进行探讨, 为学生们学习兵兵球提供良好的环境。

关键词: 微教育模式; 兵兵球教学; 教学建议

\section{引言}

作为国球的乒乓球，在各种比赛中一直被寄予厚望，这项体育运动深受广大群众的喜爱，在各类学校 的体育课上也是重要部分。乒乓球虽不及篮球、足球那么声势浩大，但是它却是需要灵活的技巧、快速的 大脑, 强大的体能为一体的高要求高标准体育运动。绝大部分学校的兵乓球教学模式都亟待改善, 老师缺 乏新的教学方法, 学生也厌倦老套的教学模式, 这导致绝大部分学校的兵乓球教学质量停滞不前。传统乒 乓球教学模式面向的群体是所有学生, 教学活动集体化, 老师不强调个体差异性, 不注重实践教学, 导致 学生学习乒乓球运动时缺乏兴趣, 缺乏自我思考与锻炼, 从而教学质量大打折扣。

\section{1 “微教育模式” 的概念}

\section{1 “微教育模式” 的含义}

微教育模式的概念来自于美国, 其主要把教学内容与规范化实践相结合, 强调细节对教学质量的影响。 虽然 “微教育模式” 从教学细节出发, 但是往往细节决定成败, 在强调细节的教学过程中学生充分理解所 学内容, 逐渐掌握知识。在运用 “微教育模式” 教学过程中, 学生积极性被调动, 学习内容简化, 老师教 学任务也会相对轻松, 学生的成绩得到有效提高。

\section{2 “微教育模式” 的特点}

微教育模式的特点主要包括以下几点: 第一、从学生出发决定教学内容。传统教育模式都是由老师决 
定自己教学的内容, 学生以老师所教的内容为中心, 这种教学模式老师占据主导地位, 学生围绕老师转。 微教育模式则改变了教学的主导地位, 以学生为中心。老师在教学前对学生进行一系列的测评, 根据学生 需求和个人特点合理安排教学内容, 不但调动了学生积极性, 而且注重学生个体化教学。第二、积极开展 针对性的实践活动。注重实践是微教育模式的一大特点, 通过实践活动学生可以把课堂上的知识与实践充 分融合, 所学知识得以运用到实践这对学生的鼓舞效果极大。通过实践才会发现知识的不足, 从而不断完 善自己的知识, 逐渐形成完整的知识体系。第三、注重教学环境的优化。当学生处于良好的教学环境中时, 学生的学习氛围以及兴趣会得到改善, 课堂上的知识接受率得到提高。第四、教学评价促进老师不断完善 教学方法。通过教学评价的方式, 既可以了解学生的学习情况, 也可以促进老师们相互交流, 共同进步。

\section{2 “微教育模式” 在乒乓球教学中运用的必要性}

时代不断进步, 各个领域都追求创新, 追求改变。“微教育模式” 是教育领域提出的完善的教学方法, 在兵乓球教学中运用 “微教育模式” 是提高当今乒乓球教学水平行之有效的方法。

\section{1 “微教育模式” 满足兵乓球学习的需求}

如今乒乓球教学需求对学生的思想素质和技能要求越来越严格, 现代教育的观念逐渐被人们接受。人 们希望不仅在学习乒乓球时学到优秀的技能, 并且体验到乒乓球的乐趣从而爱上乒乓球运动。但是乒乓球 运动是一门对技术要求以及体能要求都比较高的运动, 想要真正熟练掌握打乒乓球的技术必须要经历艰难 的学习过程。传统的理论教学以及死板的技术教学不能有效的激发学生兴趣, 导致许多学生不能真正感受 到学习乒乓球的乐趣, 甚至半途而废。微教育模式通过有规划的实践活动, 使得学生对乒乓球运动产生深 刻的理解。通过理论与实践的结合, 让学生既体验到生动的理论教学, 又可以在实践学习中密切联系理论。

\section{2 “微教育模式” 对乒乓球教学的影响}

乒乓球运动的技术要求较为细节化, 而且包含了丰富的运动技巧。一场比赛的胜负往往决定于选手对 细节的处理, 小小的失误可能导致比赛满盘皆输。微教育模式注重细节教育与实践, 乒乓球运动则是一项 注重细节的实践性体育运动。所以微教育模式可以通过实践比赛来教学, 在实践中教会学生技巧与知识。

微教育模式采取角色扮演的教学方式非常适用于丘乓球教学, 学生们通过体验不同的比赛角色, 例如 参赛选手、裁判、观众等。通过不同角色的体验, 学生可以充分理解乒乓球运动的精髓。

微教育模式教学评价是兵乓球教学中值得采纳的手段之一。通过教学评价, 有利于老师反思自己教学 过程中遇到的问题, 学生向老师反映学习过程中的心得, 老师们之间进行相互交流学习。通过镜头记录学 习过程, 老师直观的了解学习过程的优劣, 发现问题解决问题。

\section{3 “微教育模式” 在兵乓球教学中运用的建议}

在乒乓球教育中运用微教育模式主要包括以下几点, 制定科学的学习目标与计划、为学生提供良好的 学习环境、积极组织教学评价交流活动等。老师通过以上方法, 让学生对乒乓球运动产生兴趣并且充分学 习乒乓球知识与技巧, 从而乒乓球教学质量得到有效提高。

\section{1 制定学习计划与目标}

在乒乓球教学中运用 “微教育模式” 首先要根据每个学生不同的特点制定符合个人发展需要的学习 目标和计划。在制定计划的过程中要以学生的特长以及个人兴趣为主导, 根据学生学习乒乓球的需求来制 定, 而不是依靠老师的意愿来决定。在制定好目标与计划后, 老师在教学过程中以学生为主体, 注重细节 
化教育, 重视理论与实践的结合。学生在 “微教育模式” 下接受乒乓球教学, 能够细致的学习丘乓球技巧 与知识, 得到乒乓球技能与个人思想的共同提高。

\section{2 构建良好的学习环境}

在制定好个人学习目标和计划后, 乒乓球老师可以从改善学生学习环境方面着力, 其中包括教学方法、 教学内容、运动器材与场地等。教学方法改变传统的教学理念, 融入 “微教育模式” 教育的思想, 注重细 节化教育, 特异性教学。老师不能泛泛的把学生归为一类, 只进行填鸭式的教学。首先要注重改善课堂气 氛, 适当进行角色扮演练习, 激发同学们的学习兴趣。然后对同学们进行分类划教学, 根据学生特长与兴 趣进行分类教学。乒乓球运动是一项技巧丰富的体育运动, 每个学生因为不同身体素质而擅长不同的乒乓 球技术。老师应该根据学生个人特长有针对性地进行教学, 使学生在其擅长的主攻方向不断进步。此外不 能忽视教学器材与场地的建设, 为学生提供良好的学习环境, 学生在舒适的课堂上才能全心全意的投入课 堂, 接受课堂的内容, 从而逐渐爱上乒乓球运动。

\section{3 开展教学评价交流活动}

教学评价可以通过学生对老师评价, 老师之间互评, 学生对自我评价以及学生互评来进行。评价要在 课程结束后及时评价, 每个人发表自己最直接的评价, 从自身以及其他人身上吸取经验与教训。老师提供 课程评价, 发现自己课堂上的问题, 积极改善教学方法, 随时为学生解决困惑。学生提供教学评价, 认识 自己在课堂上的表现, 学习其他同学的优秀表现, 努力避免错误的发生。在最后的考核时, 老师应该针对 不同特长的学生进行不同的考核方式。乒乓球运动的学习与普通理论知识学习大不相同, 学习兵乓球主要 在于锻炼身体和学习乒乓球的竞赛技术, 让学生了解乒乓球, 丰富自己的业余生活。

\section{4 结语}

国球运动在中国的各类体育项目中占据重要地位，当前各学校也开设了乒乓球教育，然而多数乒乓球 体育课程均采用传统教学方法进行教学, 其单一的教学形式和僵化的教学模式不利于兵乓球教学效果的提 高, 传统乒乓球教学法忽视了对乒乓球战术细节的分析和教学, 多数学生都表示出对传统乒乓球教学的不 适应, 对技战术动作不理解。而乒乓球的微教育模式能解决传统乒乓球教学中的教学难题, 为师生带来新 的教学突破。在乒乓球的微教育模式中, 需要学校和教师做好以下工作。

在现代化的教育教学中, 教师应该正确树立 “微教育” 理念, 改变传统的教育理念和教学方式, 充分 进行教学调研, 在了解学生对兵乓球的学习需求的情况下合理制定出科学的教学目标, 以便在教学实践过 程中能对学生的学习进行有效的教育点拔。“微教育” 理念还要求教师要对乒乓球教学课堂进行灵活的教 学, 并以教学活动来展开乒乓球教育。好的教学方法能对学生的学习起到事半功倍的教育效果。由此, 教 师应因材施教, 关注学生个体的学习需求, 做到分层次有针对性教学。“微教育” 理念要求教师要树立角 色互换的意识, 重视让学生通过不同的角色学习乒乓球的文化和技术, 由此, 教师应当为课堂构建有激情 的情境, 提升学生的学习氛围。“微教育” 理念要求师生重视教学反思, 对摄像记录进行剖析, 瓦解学习 难题, 并解决学习难题, 从而真正掌握学习。“微教育” 理念要求师生重视课堂交流, 以此促进学习。

好的评价考核机制有利于师生的共同进步，乒乓球的微教育中，要注重评价主体的差异性，对不同层 次的学生进行不同标准的评价, 注重过程评价, 降低结果、分数评价的作用, 从而发扬乒乓球的竞技精神。

综上所述, 将微教育模式引进兵乓球的教学, 有利于教学效果的提高, 促进师生对乒乓球学习的进步, 
并让师生体验到乒乓球文化的精神内涵, 让更多的人热爱乒乓球, 学习乒乓球, 从而弘扬乒乓球文化。

\section{参考文献:}

[1] 沈连梅. 郑贺. 现代乒乓球运动发展的竞技特征与趋势研究 $[J]$. 淮北煤炭师范学院学报; 自然科学 版. 2010.31(3): $44-48$ 。

[2]郑云峰. 对重庆市乒乓球俱乐部不同年龄段学员不同教学特点的调查研究 [J].科技信息. 2010.22. 122-126.

[3] 王雨. 郭亚文. 王娟. 当今世界优秀男子乒乓球运动员年龄与身体形态分析 [J]. 体育科技文献通 报. 2010.18(9):17-21.

[4] 王利峰. 孙文玲. 项立敏. 高校乒乓球选修课创造性思维教学的实验研究 [J]. 山西师范大学学报. 社会科学 版. 2009.24(6):31-33.

[5]陈旭. 李雪梅. 韩红. 教师课堂教学技能变革的理论探讨及结构模式分析 [J]. 教师教学研究. 2005. 17 (6) :28-30.

[6]孟东方. 李天风. 创建大学工作学. 拓展高等教育研究的新视域 $[J]$. 西南大学学报; 社会科学版. 2013. 39(5) :59-176.

[7]曾茂林. 富有生命力教育理论创生过程机理探析 [J]. 西南大学学报;社会科学版. 2012. 38(1): 15-19.

[8]王远林. 刘霞. 体育教育的本真价值一生命关怀 $[J]$. 西南师范大学学报; 自然科学版. 2012.37 (8) : 168-171.

[9] 张泽承. 韩政. “微教育模式” 对于乒乓球教学的影响与实践研究 [J]. 西南师范大学学报; 自然科学 版, 2014(5):54-58.

[10]乔亚军. “微教育模式”在乒乓球教学中的影响实践研究 [J]. 当代体育科技, 2016（29)：122-133.

\section{Reference:}

[1] Shen Lianhai, Zhenghe Research on the Competitive Characteristics and Tendency of Modern Table Tennis [J]. Journal of Huaibei Coal Teachers College; Natural Science Edition. 2010.01 (3): 44-48.

[2] Zheng Yyunfeng Investigation on Different Teaching Characteristics of Students at Different Ages in Chongqing Table Tennis Club [J]. Science and Technology Information. 2010.22. 122-126.

[3] Wangyu, Guo Yawen, Wangjuan Analysis on Age and Body Shape of Elite Male Table Tennis Players in the World [J]. Journal of Sports Science and Technology Bulletin .2010.18 (9): 17-21.

[4] Wang Lifeng, Sun Wenling, Xiang Limin an Experimental Study on Creative Thinking Teaching of Table Tennis Elective Course in Colleges and Universities [J]. Journal of Shanxi Normal University. Social Science Edition. 2009.24 (6): 31-33

[5] Chenxu, Li Xuemei, Hanhong, Theoretical Discussion on the Reform of Teachers' Classroom Teaching Skills and Analysis of Structural Patterns [J]. Teacher's Teaching Research. 2005.17 (6): 28-30.

[6] Meng Dongfang, Li Tianfeng Creating a University Work and Expanding a New Horizon of Higher Education Research [J]. Journal of Southwest University; Social Science Edition. 2013.39 (5): 59-176.

[7] Zeng Maolin A Probe into the Mechanism of the Process of Creating Vitality Education [J]. Journal of Southwest University; Social Science Edition .2012.38 (1): 15-19.

[8] Wang Yuanlin, Liuxia the True Value of Physical Education - Life Concern [J]. Journal of Southwest China Normal University (Natural Science Edition) .2012.37 (8): 168-171.

[9] Zhang Zecheng, Han Zheng The Influence of "Micro - education Mode" on Table Tennis Teaching and Its Practical Research [J]. Journal of Southwest China Normal University (Natural Science Edition), 2014 (5): 54-58.

[10] Qiao Yajun a Study on the Influence of "Micro - education Mode" on Table Tennis Teaching [J]. Contemporary Sports Science and Technology, 2016 (29): 122-133. 